\title{
Hydroelectric reservoir inundation (Rio Madeira Basin, Amazon) and changes in traditional lifestyle: impact on growth and neurodevelopment of pre-school children
}

\author{
Rejane C Marques ${ }^{1}$, José G Dórea ${ }^{2, *}$, Concepta McManus ${ }^{3}$, Renata S Leão ${ }^{4}$, Katiane \\ G Brandão ${ }^{5}$, Rayson C Marques ${ }^{6}$, Igor H lto Vieira ${ }^{5}$, Jean-Remy D Guimarães ${ }^{4}$ and \\ Olaf Malm ${ }^{4}$ \\ ${ }^{1}$ Escola de Enfermagem Anna Nery, Universidade Federal do Rio de Janeiro, Rio de Janeiro, RJ, Brazil: \\ ${ }^{2}$ Department of Nutrition, Universidade de Brasilia, C.P. 04322, 70919-970 Brasilia, DF, Brazil: ${ }^{3}$ Department \\ of Animal Science, Universidade de Brasília, Brasília, DF, Brazil: ${ }^{4}$ Instituto de Biofísica Carlos Chagas Filho, \\ Universidade Federal do Rio de Janeiro, Rio de Janeiro, RJ, Brazil: ${ }^{5}$ Medical School, Universidade Federal de \\ Rondônia, Porto Velho, RO, Brazil: 'P Prefeitura Municipal de Porto Velho, Porto Velho, RO, Brazil
}

Submitted 11 February 2010: Accepted 13 July 2010: First published online 13 October 2010

\begin{abstract}
Objective: To assess the dependence on fish consumption of families and its impact on nutritional status and neurodevelopment of pre-school children.

Design: Cross-sectional study that measured children's hair mercury $(\mathrm{HHg})$ as an indicator of family fish consumption, growth (anthropometric Z-scores, WHO standards) and neurological (Gesell developmental scores (GDS)) development. Setting: Traditional living conditions among families residing in the area adjacent to the Samuel Dam (Western Amazon) hydroelectric reservoir.

Subjects: Two hundred and forty-nine pre-school children (1-59 months of age) from families transitioning from the traditional Amazonian lifestyle.

Results: Family fish consumption was significantly correlated with children's $\mathrm{HHg}$ concentration (Spearman's $r=0 \cdot 246, P<0 \cdot 0001$ ); however, HHg had no significant association with growth ( $Z$-scores). Overall, the prevalence of severe malnutrition, i.e. stunting (height-for-age $Z$-score $(\mathrm{HAZ}) \leq-3$ ), underweight (weight-for-age $Z$-score $(\mathrm{WAZ}) \leq-3$ ) and wasting (weight-for-height $Z$-score $(\mathrm{WHZ}) \leq-3$ ) was $5 \cdot 2 \%(n 13), 0 \%$ and $0 \cdot 8 \%(n 2)$, respectively. The prevalence of moderate stunting (HAZ $\geq-3$ to $\leq-2$ ), underweight (WAZ $\geq-3$ to $\leq-2$ ) and wasting (WHZ $\geq-3$ to $\leq-2)$ was $8 \cdot 8 \%(n 22), 2 \cdot 4 \%(n 6)$ and $4 \cdot 8 \%(n 12)$, respectively. Although $76 \%$ of the children showed adequate GDS ( $>85)$, multiple regression analysis showed that fish consumption (as HHg) had no impact on GDS, but that some variables did interact significantly with specific domains (motor and language development). Conclusions: The study showed that the families' shift in fish consumption had no negative impact on the growth of young children and that ensuing methylmercury exposure has not been a noticeable neurodevelopmental hindrance.
\end{abstract}

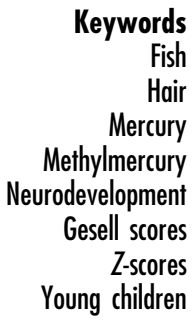

The riverine populations that inhabit the Amazon rain-forest have been subjected to changes in their lifestyle due to the region's economic development over the past 40 years. Road building, deforestation for agricultural projects and flooding of large areas for hydroelectric dams have meant that traditional subsistence lifestyles (isolated in the dense forest) are changing fast due to rural reoccupation and immigration. These events are shaping a new urban profile. Rapid urbanization is gradually replacing riverine communities and changing the traditional food supply chain.

The contrast of traditional Amazonian living conditions with new lifestyles brought by immigrants has recently been described by Piperata ${ }^{(1)}$; the use of markets for food supply is replacing the traditional dominance of fish caught by the local population as the source of animal protein. Piperata points out that the current diet of native populations is dependent on more industrialized, processed or mass-produced foods. On account of the central role of fish in the Amazon riverine diet $^{(2)}$, the key challenge in studies of nutrition transition of this population is the ability to characterize changes in the extent of fish consumption and its impact on nutritional status. Indeed, traditional communities living further from urban centres tend to have higher fish consumption ${ }^{(3)}$. Monrroy et al. ${ }^{(4)}$ 
also observed the same pattern among the more isolated and impoverished inhabitants of the Bolivian Amazon.

Owing to its natural abundance in Amazonian rivers, fish is thoroughly utilized by riverine populations ${ }^{(5)}$ as the main source of animal protein that balances their starchy $\operatorname{diet}^{(2)}$. These starchy foods are also low in essential micronutrients and are known to hinder their absorption. Fish provides abundant sulfur amino acids that neutralize the cyanogenic glucuronides present in cassava roots ${ }^{(2)}$. Essential trace minerals, such as $\mathrm{Zn}$, are significantly higher in fish than in foods with low protein content ${ }^{(6)}$. Dietary fish also enhances absorption of both $\mathrm{Zn}^{(7)}$ and $\mathrm{Fe}^{(8-10)}$ from plant foods. When prepared and eaten as a whole unit, small fish have five times more $\mathrm{Cu}$, twice as much $\mathrm{Ca}$, and two orders of magnitude more $\mathrm{Zn}, \mathrm{Fe}$ and $\mathrm{Mn}^{(11)}$. Indeed, a diet rich in fish has shown a positive effect on children's ferritin stores ${ }^{(12,13)}$. Fish consumption is positively correlated with women's iodine status; ${ }^{(14)}$ its decrease has been considered a risk for iodine deficiency in Iceland $^{(15)}$ and may have compromised adequate micronutrient nutrition in the transitioning diet of pregnant Seychelloise women ${ }^{(16)}$. Amazonian fish is a good source of Se, which is an essential nutrient also capable of counteracting the toxic effects of $\mathrm{Hg}^{(17)}$. Furthermore, both iodine and sulfur-containing amino acids provided by fish can counterbalance goitrogens in cassava-based diets produced in the iodine-depleted soils of the tropical rainforests ${ }^{(18)}$. Fish is also the main source for $n$-3 PUFA; these nutrients are important in the maternal diet during pregnancy and lactation ${ }^{(19)}$. These elongated fatty acids include DHA and EPA, which are essential for optimal neural tissue development and function ${ }^{(20)}$.

As a byproduct of the methylating bacteria abundant in the Amazon biomass, methylmercury ( $\mathrm{MeHg}$ ) is a secondary obligatory component of fish. However, the $\mathrm{MeHg}$ concentrations found in fish fluctuate as a function of the aquatic food-chain length ${ }^{(21)}$; predatory species concentrate more $\mathrm{MeHg}$ than non-predatory ones. As a consequence, Amazonian populations with high fish consumption are also exposed to $\mathrm{MeHg}^{(22)}$. The ratio of blood to hair mercury $(\mathrm{HHg})$ is high $^{(23)}$, which makes $\mathrm{HHg}$ a particularly easy and reliable biomonitor to track fish consumption ${ }^{(24)}$. Although the consumption patterns of fish vary with season, there is little overall variation in $\mathrm{MeHg}$ exposure for subsistence Amazonian populations ${ }^{(25)}$. Therefore, $\mathrm{HHg}$ has proven to be a convenient alternative to assess family fish consumption ${ }^{(25)}$, and it can also differentiate occupational and environmental $\mathrm{Hg}$ exposure in the Amazon ${ }^{(26)}$.

It has been shown previously that among native Amazonian tribes, differences in the rate of fish consumption (127g fish/d v. $30 \mathrm{~g}$ fish/d) were compensated by other protein sources that showed no significant correlation with the attained growth of Amer-Indian children ${ }^{(27)}$. Subsequent studies with an urban Amazonian population indicated that the habitual dominance of fish consumption, although important for some nutrients, can be successfully replaced by other animal food sources ${ }^{(28)}$.

The Amazonian forest environment, especially in the state of Rondonia (western region), has undergone dramatic change over the past 40 years. It started with the gold rush in the 1970s, then the opening of roads and agricultural projects, which attracted people from different parts of the country. Land occupation by agriculture, logging, mining operations and ensuing urbanization have created a demand for energy that has been met with the construction of large hydroelectric dams. As a consequence, water reservoirs have flooded extensive forest areas, resulting in the displacement of traditional subsistence living. The reservoir of the Samuel Dam (a hydroelectric plant that provides most of the electricity consumed in the state of Rondonia) was flooded in 1988, and the present study is the first one that looks into the impact, brought about by relocation, on the traditional lifestyle of families that lived in the inundated areas. Fearnside ${ }^{(29)}$ has addressed the environmental costs of the flooded forest and fish contamination resulting from methylation of $\mathrm{Hg}$ present in the soil of the Samuel Dam, as well as examining the social costs of the dam in terms of resettlement of families.

The objective of the present paper was to study the dependence on fish consumption of families (a result of transitioning from a traditional lifestyle) and its impact on nutritional status and neurodevelopment of children under 5 years of age.

\section{Materials and methods}

This was part of an ongoing study to evaluate the impact of land occupation (mining, agricultural resettlement) on the general health and nutrition status of pre-school children (under 5 years of age). The protocol for the present study was approved by the Ethics Committee for Studies in Humans of the Federal University of Rondonia. Written consent (stating that participation was voluntary and confidentiality was assured) was provided by the participant mother, who could withdraw from the study at any time. The study took place between February 2006 and December 2007, over which time several visits were undertaken.

The study area in Fig. 1 illustrates the Samuel Hydroelectric Dam area and the adjacent villages of the studied population (scattered in the municipalities of Candeias do Jamari and Itapuã d'Oeste) along the Rio Jamari (a tributary of the Rio Madeira). These villages were formed principally (but not exclusively) by riverine communities that were displaced by the compulsory confiscation of lands for the Samuel reservoir; in these villages we found rural workers as well as people who continued fishing for a living. The studied population consisted of six communities designated on the map (Pescadores, Linha Azul, Triunfo, Rei do Peixe, Comunidade do Rio Preto do Crespo and Garimpo Clandestino). Most of these families were still living without basic 


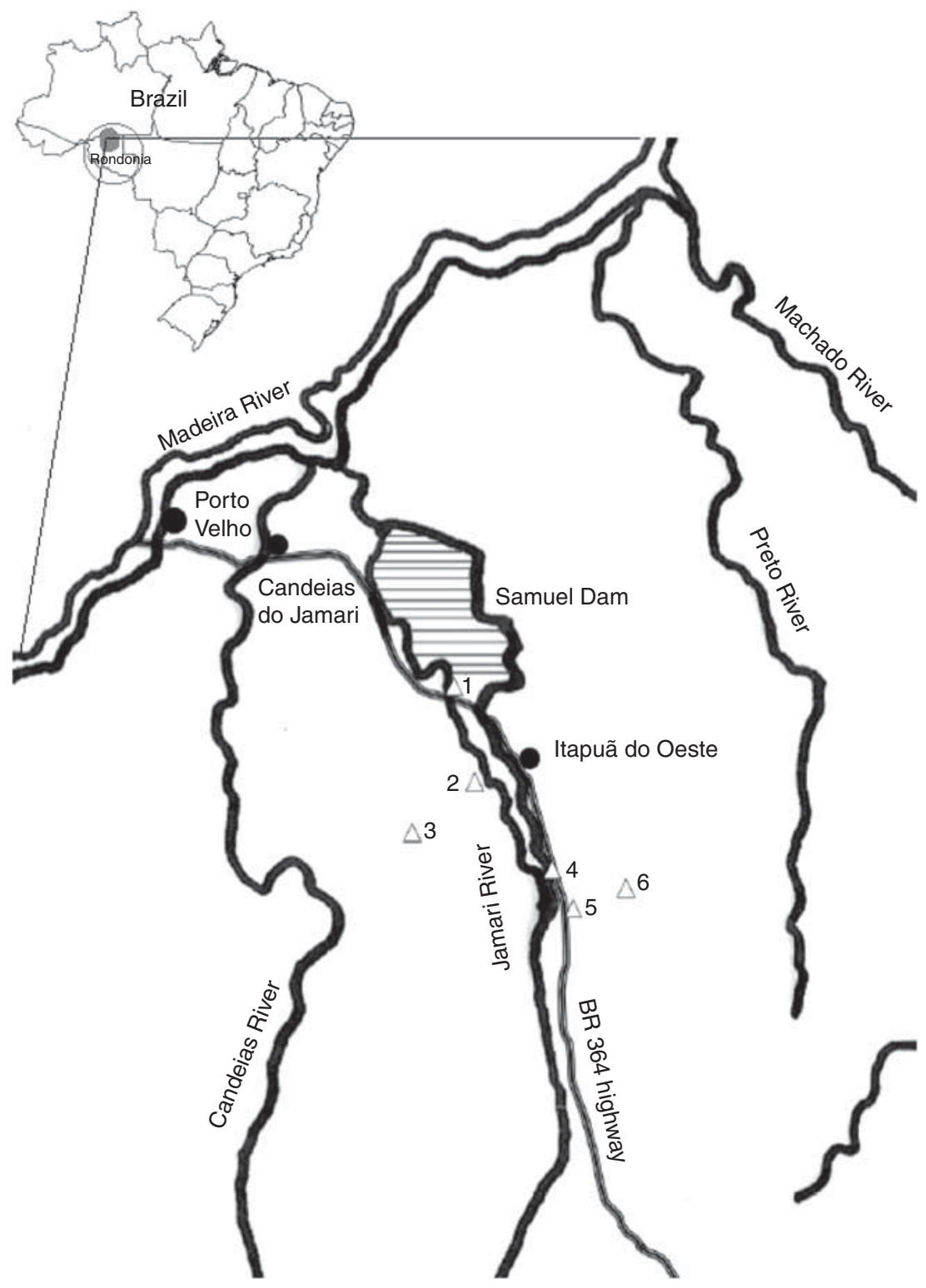

Fig. 1 Map of the studied area with designated communities (1, Vila dos Pescadores; 2, Linha Azul; 3, Triunfo; 4, Rei do Peixe; 5, Comunidade do Rio Preto do Crespo; 6, Garimpo Clandestino)

health and sanitation and the children attended a compromised school system. The nearest hospital and school were located $19 \mathrm{~km}$ away in the town of Itapuã d'Oeste.

\section{Data collection}

During visits, a questionnaire was used to collect data on general aspects of demographics and, especially, information on family fish consumption. A trained interviewer applied the questionnaire to obtain demographic information, number of persons per home, family income and related maternal (educational level and breast-feeding practices) variables. Each family was interviewed and examined on a single occasion. They were asked how many fish meals were consumed daily; in order to complement fish intake information, hair was also collected from the children who were studied. Samples of hair were taken from all pre-school children $(<5$ years of age) after recording age (birth certificate) and measuring height and weight. Stainless steel scissors were used to cut the hair close to the scalp, always in the same occipital area. The sampled hair was bundled together and placed in a labelled envelope and taken to the Radioisotopes Laboratory of the Federal University of Rio de Janeiro for analysis.

\section{Anthropometric and neurodevelopment measurements}

Weight and height (length in young children) were measured by trained nurses according to standard procedures ${ }^{(30)}$. Length of babies and infants was measured in recumbent position with a $0 \cdot 1 \mathrm{~cm}$ stadiometer. The standing 
height (to the nearest $0 \cdot 1 \mathrm{~cm}$ with a stadiometer) and weight (to the nearest $0 \cdot 1 \mathrm{~kg}$ with an electronic scale) were measured in older children, who were dressed solely in underwear and barefoot. Weight $(\mathrm{kg})$ and height $\left(\mathrm{m}^{2}\right)$ were used to calculate BMI $\left(\mathrm{kg} / \mathrm{m}^{2}\right)$. Z-scores for attained weight-for-age (WAZ), height/length-for-age (HAZ), BMI-for-age and weight-for-length (WHZ) were based on the WHO Child Growth Standards (WHO Multicentre Growth Reference Study Group) ${ }^{(31)}$, and were calculated using WHO Anthro version 2 (Department of Nutrition, WHO, Geneva) and the WHO recommended growth curves.

The Gesell developmental schedules (GDS), which have been revised and adopted to be used in Brazil ${ }^{(32,33)}$, were applied by trained professionals to evaluate neurodevelopment reactions (voluntary, spontaneous or learned) and reflexes. Postural reactions, hand pressure, locomotion and coordination, constructive ability (which is influenced by motor development), visible and audible communication, individual reactions regarding people and stimulations (depending mainly on the temperament of the child and the surroundings) were also evaluated. The results were expressed as developmental scores (or development quotient, DQ) of the specific domains: Adaptive ability, Language development and Motor abilities (gross motor) and Personal-social ability. These were joined to give a single number (mean of the four domains in percentage).

The GDS was conceived to provide a neurological and intellectual evaluation of children and is widely used in several countries ${ }^{(34)}$. Tang et $a l^{(34)}$ described the GDS application, stressing its adoption by the WHO for use in resource-poor settings. The DQ was standardized (100). A DQ of 85 is considered to be the cut-off point for determining normal and developmental delay; a $\mathrm{DQ}<85$ suggests a child with a high probability of some organic impairment. DQ of 70-85 is indicative of moderate delay, whereas DQ $<70$ indicates severe delay. The GDS has a significant correlation with mental development at 6-7 years as measured by an adapted version of the Wechsler Intelligence Scales for Children ${ }^{(34)}$.

\section{Hair mercury determination}

Hair sample preparation and analytical procedures to determine total $\mathrm{Hg}$ concentrations were performed according to standardized laboratory procedure ${ }^{(35)}$. Briefly, the hair samples were weighed and digested before analysis. The samples were comminuted with stainless steel scissors and washed with EDTA $0 \cdot 01 \%(\mathrm{w} / \mathrm{v})$, then dried in an oven at $50^{\circ} \mathrm{C}$. The hair was then digested at $80^{\circ} \mathrm{C}$ for 40 min with concentrated $\mathrm{HNO}_{3}(3 \mathrm{ml})$ and $\mathrm{KMnO}_{4}(5 \%$ $(\mathrm{w} / \mathrm{v}) ; 6 \mathrm{ml}$ ) in a microwave oven system for $35 \mathrm{~min}$ (MDS 2000; CEM Corporation, Matthews, NC, USA). The determination of total $\mathrm{Hg}$ was made by cold vapour atomic absorption spectrometry (CV-AAS) with a flow injection system FIMS 400; Perkin-Elmer, Ueberlingen, Germany). Precision and accuracy of $\mathrm{Hg}$ determinations were assured by the use of internal standards, use of triplicate analyses of samples and certified reference materials (IAEA-085 and 086, Vienna, Austria) with recoveries of $92 \%$. All glassware used was washed clean, rinsed with $5 \%(\mathrm{w} / \mathrm{v})$ EDTA and double distilled water and left to rest in $5 \%(\mathrm{w} / \mathrm{v}) \mathrm{HNO}_{3}$ overnight. Then it was rinsed again in double-distilled water and dried at $100^{\circ} \mathrm{C}$ for $12 \mathrm{~h}$.

\section{Statistical analysis}

Data summarization (means, SD, changes in variables) and correlation analysis were carried out by statistical packages. Prism software version 10IC (GraphPad Software Inc., San Diego, CA, USA) was used to generate graphs and determine Spearman's ( $\rho$ ) correlation to examine the strength of association between $\mathrm{HHg}$ (marker of fish consumption) and neurological and anthropometric measures. Multiple regression (stepwise) statistical analysis to test the effect of variables on children's attained growth and DQ was further carried out using the SAS statistical software package version $6 \cdot 0$ (SAS Institute, Cary, NC, USA).

\section{Results}

The general characteristics of the studied population are summarized in Table 1 . The majority of the families consumed fish less than three times per week, whereas fish consumption on a daily basis was currently reported by only $10 \%$ of the families (Table 1 , Fig. 2). Nevertheless, the correlation between family fish intake and children's $\mathrm{HHg}$ concentration was statistically significant (Spearman's $r=0 \cdot 2480, P<0 \cdot 0001)$. The cumulative frequency of $\mathrm{HHg}$ concentrations (reflecting fish consumption) in pre-school children is shown in Fig. 3; median $\mathrm{HHg}$ concentration was $3.95 \mu \mathrm{g} / \mathrm{g}$. Despite the variation in fish consumption, the correlation between children's HHg and the attained $Z$-scores was not statistically significant.

The nutritional status of these pre-school children is shown in Fig. 4 as the cumulative distribution of $Z$-scores. Overall, the prevalence of severe malnutrition, i.e. stunting (HAZ $\leq-3)$, underweight $(\mathrm{WAZ} \leq-3)$ and wasting

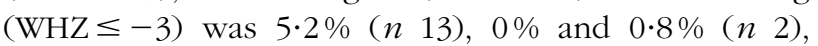
respectively. The prevalence of moderate stunting (HAZ $\geq-3$ to $\leq-2$ ), underweight (WAZ $\geq-3$ to $\leq-2$ ) and wasting (WHZ $\geq-3$ to $\leq-2$ ) was $8 \cdot 8 \%$ ( $n$ 22), $2 \cdot 4 \%(n 6)$ and $4 \cdot 8 \%(n 12)$, respectively.

Regarding effects of $\mathrm{MeHg}$ exposure (in consumed fish) and neurobehavioral effects, $32 \cdot 1 \%$ of the preschool children had $\mathrm{HHg}$ concentrations above $5 \mathrm{ppm}$ (Fig. 3), but only $3 \cdot 8 \%$ showed an indication of compromised GDS below $70 \%$ (Fig. 5). Indeed, in the bivariate model, there was also no statistically significant correlation between $\mathrm{HHg}$ concentrations and GDS scores. However, the stepwise regression model, which included constitutional (age, birth weight, birth length, anthropometric measures) and environmental $(\mathrm{HHg}$, total $\mathrm{Hg}$ in 
Table 1 General characteristics related to the frequency of fish consumption (including $\mathrm{HHg}$ concentrations) and anthoropometric data of children ( $n$ 249) enrolled in the study

\begin{tabular}{|c|c|c|c|c|c|}
\hline & Mean & SD & Minimum & Median & Maximum \\
\hline \multicolumn{6}{|l|}{ FAMILY } \\
\hline Fish consumption (meals/week) & $2 \cdot 9$ & $2 \cdot 3$ & $0 \cdot 0$ & $2 \cdot 0$ & $>7 \cdot 0$ \\
\hline Family members & $5 \cdot 8$ & $2 \cdot 2$ & $3 \cdot 0$ & $5 \cdot 0$ & $14 \cdot 0$ \\
\hline Family income (US\$) & $232 \cdot 63$ & $210 \cdot 11$ & $55 \cdot 56$ & $148 \cdot 15$ & $1666 \cdot 67$ \\
\hline Breast-feeding (months) ${ }^{\star}$ & $11 \cdot 9$ & 8.9 & $0 \cdot 0$ & $12 \cdot 0$ & $11 \cdot 9$ \\
\hline Maternal education (years) & $6 \cdot 51$ & $3 \cdot 5$ & $0 \cdot 0$ & $6 \cdot 0$ & $16 \cdot 0$ \\
\hline \multicolumn{6}{|l|}{ CHILDREN } \\
\hline \multicolumn{6}{|l|}{ Birth } \\
\hline Weight (kg) & $3 \cdot 24$ & 0.43 & $2 \cdot 01$ & $3 \cdot 15$ & $5 \cdot 25$ \\
\hline Length (cm) & $50 \cdot 5$ & $2 \cdot 4$ & $45 \cdot 0$ & $50 \cdot 0$ & $58 \cdot 0$ \\
\hline Age at visit (months) & $26 \cdot 1$ & $15 \cdot 7$ & $1 \cdot 0$ & $24 \cdot 0$ & $59 \cdot 0$ \\
\hline \multicolumn{6}{|l|}{ Current } \\
\hline Weight (kg) & $11 \cdot 90$ & $3 \cdot 57$ & $3 \cdot 3$ & $11 \cdot 60$ & $20 \cdot 5$ \\
\hline Height $(\mathrm{cm})$ & $84 \cdot 4$ & $14 \cdot 6$ & $50 \cdot 0$ & $84 \cdot 0$ & $115 \cdot 0$ \\
\hline WHZ & $0 \cdot 21$ & $1 \cdot 3$ & $-3 \cdot 72$ & 0.09 & $4 \cdot 01$ \\
\hline HAZ & -0.49 & $1 \cdot 4$ & $-4 \cdot 61$ & -0.54 & $3 \cdot 48$ \\
\hline WAZ & $-0 \cdot 12$ & $1 \cdot 0$ & $-2 \cdot 87$ & $-0 \cdot 11$ & 3.04 \\
\hline $\mathrm{Hg}$ as TCV & $109 \cdot 2$ & $49 \cdot 5$ & $0 \cdot 0$ & $137 \cdot 50$ & $212 \cdot 50$ \\
\hline Infant's HHg $(\mu \mathrm{g} / \mathrm{g})$ & $4 \cdot 33$ & $1 \cdot 7$ & 1.04 & 3.95 & $9 \cdot 22$ \\
\hline
\end{tabular}

$\mathrm{HHg}$, total hair mercury concentrations; WHZ, weight-for-height Z-score; HAZ, height-for-age Z-score; WAZ, weight-for-age Z-score; TCV, thimerosal-containing vaccine.

*Thirty-eight of 249 mothers were still breast-feeding and only thirteen never breast-fed.

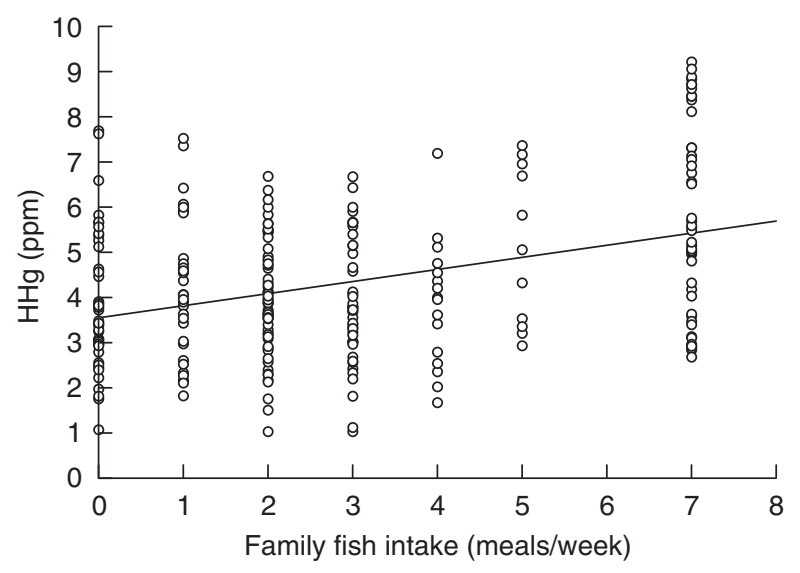

Fig. 2 Spearman's correlation of family fish consumption and attendant total hair mercury $(\mathrm{HHg})$ concentrations in preschool children

thimerosal-containing vaccine (TCV), frequency of fish consumed, breast-feeding, family size, income and maternal school-years) variables, showed that only specific domains could significantly interact with specified variables. In the multivariate model (Table 2), HHg was not a risk factor that could affect the general development (GD) score; only the language domain was shown to be significantly influenced by $\mathrm{HHg}$.

It seems that anthropometric attainment had no apparent impact on neurodevelopment (GD scores). Indeed, only the WAZ was significantly associated with the language domain, and birth length was associated with adaptive and personal Gesell scores. The distribution of GD scores is illustrated in Table 3 as a function of the main factors known to influence child neurodevelopment. Invariably, for all the considered factors (children's growth standards and $\mathrm{HHg}$, maternal age

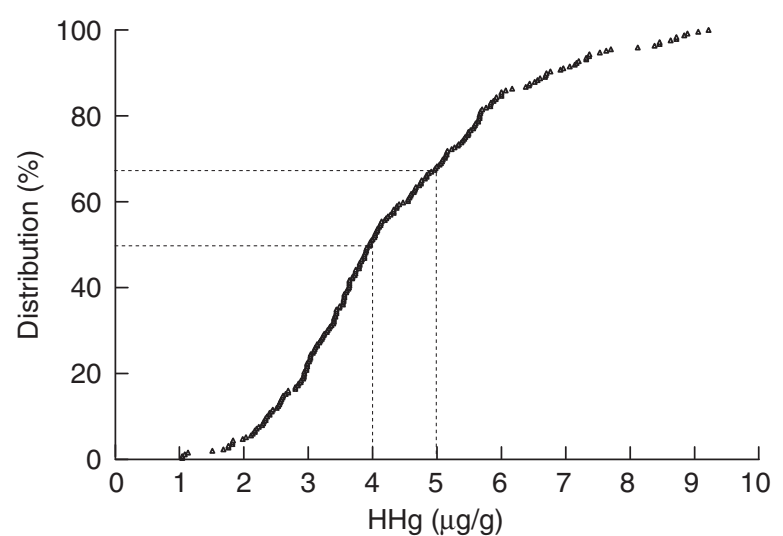

Fig. 3 Cumulative frequency distribution of total hair mercury $(\mathrm{HHg})$ exposure in pre-school children; this is a proxy of frequency of fish consumption

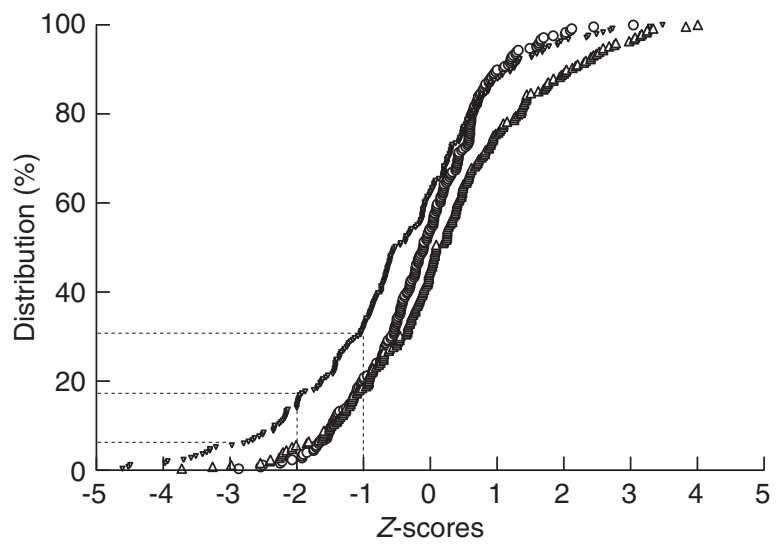

Fig. 4 Cumulative frequency distribution of attained anthropometric measurements (Z-scores) of children under 5 years of age ( $\triangle$, weight-for-height; $\boldsymbol{\nabla}$, height-for-age; $\bigcirc$, weight-for-age) 
and school-years, family income and fish meals) not only were the mean values close but also great variation existed.

In this cross-sectional sample of children, breast-feeding practices were high; median duration was 12 months. In all, $94 \%$ of infants younger than 6 months were reported to be or had been breast-fed, whereas only $5 \%$ of the children overall were reported to have never been breast-fed. Considering that this was a cross-sectional study, the mean breast-feeding duration may have been

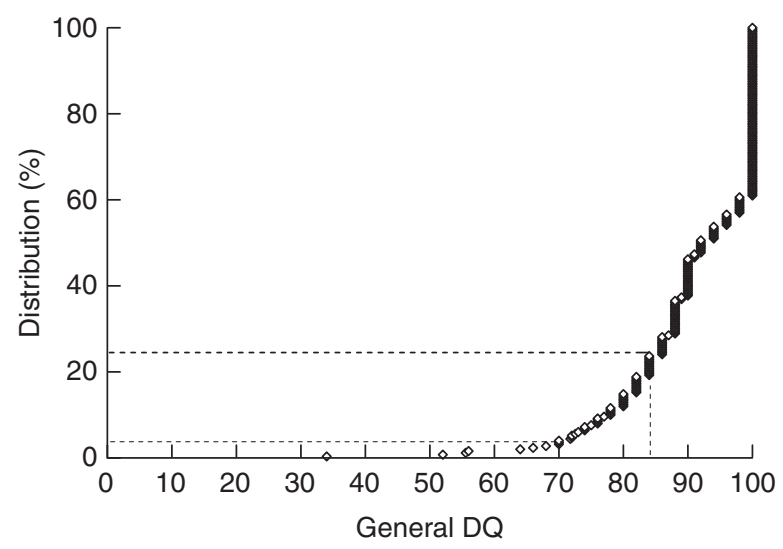

Fig. 5 Cumulative frequency distribution of Gesell general development scores (DQ, development quotient) even higher. In the present circumstances, breast-feeding was not significantly associated with GDS.

\section{Discussion}

The environmental effects of reservoir flooding have dramatically changed the Amazon landscape, impacting its biota and affecting the lifestyle of the subsistence population. The present study is the first one addressing the changes in fish consumption (and attendant $\mathrm{MeHg}$ exposure) and their effects on children's nutritional status and neurodevelopment. The study revealed that $\mathrm{HHg}$ concentrations in pre-school children were much lower than in the recent past as a result of diminished fish consumption. This proxy of fish consumption (biomarker of $\mathrm{MeHg}$ exposure) indicated that changing the centrality of fish in the diet was not the main determinant of children's growth and neurodevelopment. Nevertheless, given the still relatively high consumption of fish and attendant essential nutrients (especially PUFA), this could be an attenuating factor in the exposure to $\mathrm{MeHg}$.

Although the median $\mathrm{HHg}$ concentration in the studied families was relatively low compared to subsistence populations $^{(25)}$, the pattern of fish consumption was still variable (Table 1). Compared to traditional subsistence families

Table 2 Multivariate linear regression model (showing variables that met the 0.050 significance level) to estimate the effect of infant early exposure to mercury (that included ethylmercury in thimerosal vaccines) and maternal variables on the Gesell development scores* of 249 pre-school children ( $0-5$ years)

\begin{tabular}{|c|c|c|c|c|c|c|c|c|c|c|}
\hline & \multicolumn{2}{|c|}{ Motor } & \multicolumn{2}{|c|}{ Language* $^{*}$} & \multicolumn{2}{|c|}{ Adaptive* $^{*}$} & \multicolumn{2}{|c|}{ Personal $^{*}$} & \multicolumn{2}{|c|}{ General (\%) } \\
\hline & $\beta$ & $P$ & $\beta$ & $P$ & $\beta$ & $P$ & $\beta$ & $P$ & $\beta$ & $P$ \\
\hline $\mathrm{HHg}(\mathrm{ppm})$ & - & - & $-1 \cdot 265$ & 0.027 & - & - & - & - & - & - \\
\hline Maternal school-years & 0.678 & 0.015 & - & - & 0.383 & $0 \cdot 126$ & - & - & - & - \\
\hline Home density & 0.722 & 0.094 & - & - & - & - & - & - & - & - \\
\hline Birth length & - & - & - & - & -0.660 & 0.067 & -0.633 & 0.0257 & - & - \\
\hline WAZ & - & - & -1.989 & 0.046 & - & - & - & - & - & - \\
\hline Income & - & - & - & - & - & - & -0.002 & 0.044 & - & _ \\
\hline
\end{tabular}

$\mathrm{HHg}$, total hair mercury concentrations; WAZ, weight-for-age Z-score.

*Domains showing (or approaching) statistically significant interactions.

Table 3 Frequency distribution of neurodevelopment (Gesell schedules) of children and summary of corresponding markers of mercury exposure and relevant measured variables

\begin{tabular}{|c|c|c|c|c|c|c|c|c|}
\hline & \multicolumn{8}{|c|}{ Developmental quotients } \\
\hline & \multicolumn{2}{|c|}{$<70$} & \multicolumn{2}{|c|}{$70-85$} & \multicolumn{2}{|r|}{$>85$} & \multicolumn{2}{|c|}{ Overall } \\
\hline & Median & Range & Median & Range & Median & Range & Median & Range \\
\hline$n(\%)$ & \multicolumn{2}{|c|}{$7(3)$} & \multicolumn{2}{|c|}{$52(21)$} & \multicolumn{2}{|c|}{$190(76)$} & \multicolumn{2}{|c|}{$249(100)$} \\
\hline Age (months) & 27 & $12-36$ & 24 & $1-59$ & 24 & $1-58$ & 24 & $1-59$ \\
\hline $\mathrm{HHg}(\mu \mathrm{g} / \mathrm{g})$ & $4 \cdot 14$ & $2 \cdot 36-6 \cdot 60$ & $4 \cdot 27$ & $2 \cdot 17-8 \cdot 38$ & $3 \cdot 83$ & $1 \cdot 04-9 \cdot 22$ & 3.96 & $1 \cdot 04-9 \cdot 22$ \\
\hline Mother's education (years) & 2 & $0-8$ & 6 & $0-15$ & 6 & $0-15$ & 6 & $0-15$ \\
\hline Income (\$US/month) & $207 \cdot 41$ & $74 \cdot 1-822 \cdot 2$ & $207 \cdot 41$ & $18 \cdot 5-1222 \cdot 2$ & $148 \cdot 15$ & $55 \cdot 6-1666 \cdot 7$ & $166 \cdot 67$ & $18 \cdot 5-1666 \cdot 7$ \\
\hline WHZ & 0.05 & $-2 \cdot 23-3 \cdot 15$ & 0.44 & $-3 \cdot 26-4 \cdot 01$ & -0.06 & $-3 \cdot 31-2 \cdot 15$ & 0.09 & $-3 \cdot 72-4 \cdot 01$ \\
\hline HC Z-score & -0.93 & $-2 \cdot 02-0.34$ & -0.63 & $-3.59-0.79$ & -0.62 & $-3 \cdot 31-2 \cdot 15$ & -0.63 & $-3 \cdot 59-2 \cdot 15$ \\
\hline Fish consumption (meals/week) & 3 & $1-4$ & 2 & $0-7$ & 2 & $0-7$ & 2 & $0-7$ \\
\hline Breast-feeding (months) & 12 & $3-24$ & 12 & $0-36$ & $11 \cdot 5$ & $0-45$ & 12 & $0-45$ \\
\hline
\end{tabular}

$\mathrm{HHg}$, total hair mercury concentrations; WHZ, weight-for-height $Z$-score; HC, head circumference. 
from the Rio Madeira Basin ${ }^{(25)}$, fish consumption is losing predominance in transitioning populations. Many families were eating less than one fish meal per week (Fig. 2). In this situation, it seemed that dietary protein requirements for children's growth were met by sources other than fish. This is in agreement with previous studies in Amazonian Amer-Indians ${ }^{(27)}$ and urban pre-school children from Porto Velho ${ }^{(28)}$.

A relatively small percentage of children could be classified as malnourished (Fig. 4). We can speculate that, at least for older children, protein sources (other than fish) were adequately replaced. The nutritional value of fish to combat micronutrient deficiencies in developing countries is widely recognized $^{(36)}$ and, indeed, fish plays a central role in sustaining health and nutritional status of native communities of the Rio Madeira $\operatorname{Basin}^{(4,37,38)}$. Among people still living traditionally, Benefice et al. ${ }^{(33)}$ showed a significant relationship between $\mathrm{HHg}$ and nutritional indices in 5-10-year-old children, but not in the younger age group. The children reported by Benefice et $a l^{(37)}$ had $\mathrm{HHg}$ concentrations $(3.9 \mathrm{ppm})$ comparable to the studied pre-school children. However, in the Brazilian Amazonian populations' transitioning lifestyles, their less habitual fish consumption (diminishing $\mathrm{HHg}$ concentrations) did not determine the attained anthropometric scores. Anaemia and intestinal parasites are still a public health problem for Amazonian children $^{(39)}$; and although we did not take such variables into account, the percentages of children in the present study who were classified as malnourished are higher than reported recently for pre-school children in two Amazon towns in the neighbouring state of Acre ${ }^{(39)}$

Since fish is still an important item in the diet of Western Amazonians, it is possible to compare fish consumption in this fast-changing environment and the attendant lifestyle of populations. Compared to 5-year-old children (2.6 ppm) of urban families ${ }^{(28)}$, our children older than 36 months had a higher mean $\mathrm{HHg}$ concentration ( $4.7 \mathrm{ppm})$. However, this was much lower than the mean $\mathrm{HHg}$ observed in children of subsistence families still living traditionally. In the Puruzinho village $(320 \mathrm{~km}$ from the present study site), the children had a mean $\mathrm{HHg}$ concentration of $18.4 \mathrm{ppm}$, which was clearly different from a median $\mathrm{HHg}$ concentration $(0.3 \mathrm{ppm})$ in Brazilian children who did not consume fish ${ }^{(35)}$. Our mean values, however, are within the value range for children from villages along the Rio Tapajós (Eastern Amazonia) reported by Pinheiro et al. ${ }^{(40)}$.

Early studies addressing high fish consumption in subsistence adult villagers of the Rio Madeira Basin showed elevated $\mathrm{HHg}$ concentrations as high as $90 \cdot 6-303 \cdot 1 \mathrm{ppm}$ without apparent neurological syndromes ${ }^{(41)}$. Nevertheless, Passos and Mergler ${ }^{(42)}$ summarized neurobehavioral studies in Amazonian children showing that higher mean $\mathrm{HHg}$ levels $(>10 \mathrm{ppm})$ tended to show a significant decrease in some tests (vision acuity, muscle performance, motor functions, neurobehavioural), whereas studies of children with lower mean $\mathrm{HHg}(<5 \mathrm{ppm})$ showed no significant effects on the tested neurobehavioral functions. Since then, some studies have compared Amazonian subsistence populations or high fish eaters against low fish eaters. Comparing Wayama children (French Guiana) with Brazilian children from the Rio Tapajós (both Amazonian fish-eating populations), Chevrier et $a l^{(43)}$ reported increased risks of making rotation or simplification errors in the drawings made by the Rio Tapajós children. The Brazilian children had twice the mean levels of $\mathrm{HHg}$ concentrations of those from French Guiana. Although fish $\mathrm{MeHg}$ could be a determinant of the small differences in neurobehavioural tests, there were other ecological and $\mathrm{Hg}$ exposure factors that differentiated French Guianese and Brazilian children.

Pre- and postnatal $\mathrm{Hg}$ exposure between the two Amazonian populations studied by Chevrier et al. ${ }^{(43)}$ was associated with differences in schedule and type of vaccines used in French Guiana and Brazil ${ }^{(44)}$. In addition to having successful coverage of tetanus vaccine during pregnancy, the immunization schedule in Brazil starts at birth with hepatitis B, with a TCV (that degrades into ethylmercury) as a preservative. In French Guiana, these vaccines are available free of thimerosal. However, breast-fed children do overcome sensitivity to early $\mathrm{Hg}$ exposure (which also includes vaccine ethylmercury) as measured by neurobehavioural tests at 5 years of age; ${ }^{(45)}$ the effects of breast-feeding on improved performance of neurobehavioural tests have been established and partly attributed to high concentrations of PUFA ${ }^{(46)}$. Furthermore, comparing the high fish consumption of subsistence riverine children (Western Amazon) with those who rarely ate fish, a striking difference in $\mathrm{HHg}$ (fiftyeight times) was seen, but no significant differences in the results of neurocognitive tests ${ }^{(35)}$. The nutritional substances in fish (most likely PUFA) may attenuate the neurotoxic effect of $\mathrm{MeHg}$. Indeed, studies have shown that greater maternal fish consumption is associated with improved child neurodevelopment ${ }^{(47)}$.

Both childhood malnutrition ${ }^{(48)}$ and early (pre- and postnatal) exposure to neurotoxic $\mathrm{MeHg}^{(49)}$ can be negatively associated with neurocognition tests later in life. It is also acknowledged that social factors are capable of affecting neurocognition. Studies have frequently found an association between mothers' and children's intellectual test scores ${ }^{(50)}$. Cheung and Ashorn ${ }^{(51)}$ reported that cognitive and academic achievements were sensitive to linear growth in Filipino children. Although none of the maternal variables had any significant effect on GD, the number of maternal school-years showed a significant association with motor development. It appears that other environmental and nutritional alternatives were determining nutritional status of children while not affecting their neurodevelopment.

The uniqueness of addressing two determinants of nutrition (high-quality protein of nutrient-dense fish) and 
neurotoxic exposure ( $\mathrm{MeHg}$ ) at the sensitive developmental age (1-59 months) also carried several limitations. As this was a transversal descriptive study, variability in neurological development related to age was one of them. Other limitations lay with the possibility of missing confounding factors, difficult to properly adjust in observational design. Family income is a very crude assessment to estimate various differences in health characteristics of the home and living conditions that might interfere with both growth and neurodevelopment. Nevertheless, regarding fish consumption, $\mathrm{HHg}$ concentrations have proven a more reliable biomarker because of their integrative power ${ }^{(25)}$. It is an important continuous variable to measure in association with growth and neurodevelopment.

The present research added information regarding changes in fish consumption in transitioning lifestyles of Amazonian populations where fish has long been central as a protein source. It showed that families' shift from a fish-rich diet had no negative impact on the growth of young children and that the ensuing $\mathrm{MeHg}$ exposure was not a noticeable neurodevelopmental hindrance.

\section{Acknowledgements}

The present study was partly supported by the National Research Council of Brazil-CNPq (CT-HIDRO, project555516/2006-7; CT-AMAZONIA, project-575573/2008-2. The authors declared that they have no competing financial interests. R.C.M. helped in design of the project, supervision of field trips, anthropometry training of young investigators, data organization and writing of the manuscript; J.G.D. contributed to the planning and supervision of the study, organization and analysis of the data and writing of the manuscript; C.M. contributed to the statistical analysis of data and discussion of results; K.G.B., R.C.M. and I.H.I.V. contributed to the anthropometric measurements and neurological assessment of children; R.S.L. performed mercury determination in hair samples; J.R.D.G. and O.M. performed laboratory supervision for hair analysis and $\mathrm{Hg}$ determination and discussion of results. The authors thank the mothers who gracefully participated in the study, the Secretaria de Saúde de Itapuã D'Oeste, and Elen Noujain, Rogério Monteiro, José Luiz Lazarini Jr and Verusca G Santos for their dedication.

\section{References}

1. Piperata BA (2007) Nutritional status of Ribeirinhos in Brazil and the nutrition transition. Am J Phys Anthropol 133, 868-878.

2. Dórea JG (2004) Cassava cyanogens and fish mercury are high but safely consumed in the diet of native Amazonians. Ecotoxicol Environ Saf 57, 248-256.

3. Alves MF, Fraiji NA, Barbosa AC et al. (2006) Fish consumption, mercury exposure and serum antinuclear antibody in Amazonians. Int J Environ Health Res 16, 255-262.
4. Monrroy SX, Lopez RW, Roulet M et al. (2008) Lifestyle and mercury contamination of Amerindian populations along the Beni river (lowland Bolivia). J Environ Health $\mathbf{7 1}$, $44-50$.

5. Dufour DL (1991) Diet and nutritional status of Ameridians: a review of the literature. Cad Saude Publica 7, 481-502.

6. Terrés C, Navarro M, Martín-Lagos F et al. (2001) Zinc levels in foods from southeastern Spain: relationship to daily dietary intake. Food Addit Contam 18, 687-695.

7. Garcia-Arias MT, Castrillon AM \& Navarro MP (1993) Bioavailability of zinc in rats fed on tuna as a protein source in the diet. J Trace Elem Electrolytes Health Dis 7, 29-36.

8. Layrisse M, Martínez-Torres C, Méndez-Castellano H et al. (1990) Relationship between iron bioavailability from diets and prevalence of iron deficiency. Food Nutr Bull 12, 301-309.

9. Gibson RS \& Hotz C (2001) Dietary diversification/ modification strategies to enhance micronutrient content and bioavailability of diets in developing countries. $\mathrm{Br} J$ Nutr 85, Suppl. 2, S159-S166.

10. Navas-Carretero S, Pérez-Granados AM, Sarriá B et al. (2008) Oily fish increases iron bioavailability of a phytate rich meal in young iron deficient women. J Am Coll Nutr 27, 96-101.

11. Larsen T, Thilsted SH, Kongsbak K et al. (2000) Whole small fish as a rich calcium source. Br J Nutr 83, 191-196.

12. Michaelsen KF, Milman N \& Samuelson G (1995) A longitudinal study of iron status in healthy Danish infants: effects of early iron status, growth velocity and dietary factors. Acta Paediatr 84, 1035-1044.

13. Gunnarsson BS, Thorsdottir I \& Palsson G (2007) Associations of iron status with dietary and other factors in 6-yearold children. Eur J Clin Nutr 61, 398-403.

14. Zollner H, Below H, Franke G et al. (2001) Present alimentary supply of iodine in Western Pomerania. Deut Lebens-Runds 97, 376-380.

15. Gunnarsdottir I, Gustavsdottir AG \& Thorsdottir I (2009) Iodine intake and status in Iceland through a period of 60 years. Food Nutr Res 53; doi:10.3402/fnr.v53i0.1925.

16. Bonham MP, Duffy EM, Robson PJ et al. (2009) Contribution of fish to intakes of micronutrients important for fetal development: a dietary survey of pregnant women in the Republic of Seychelles. Public Health Nutr 12, 1312-1320.

17. Dórea JG, Moreira MB, East G et al. (1998) Selenium and mercury concentrations in some fish species of the Madeira River, Amazon Basin, Brazil. Biol Trace Elem Res 65, 211-220.

18. Dórea JG (2003) Fish are central in the diet of Amazonian riparians: should we worry about their mercury concentrations? Environ Res 92, 232-244.

19. Rice R (1996) Fish and healthy pregnancy: more than just a red herring! Prof Care Mother Child 6, 171-173.

20. Koletzko B, Lien E, Agostoni C et al. (2008) World Association of Perinatal Medicine Dietary Guidelines Working group. The roles of long-chain polyunsaturated fatty acids in pregnancy, lactation and infancy: review of current knowledge and consensus recommendations. J Perinat Med 36, 5-14.

21. Barbosa AC, de Souza J, Dórea JG et al. (2003) Mercury biomagnification in a tropical black water, Rio Negro, Brazil. Arch Environ Contam Toxicol 45, 235-246.

22. Barbieri FL \& Gardon J (2009) Hair mercury levels in Amazonian populations: spatial distribution and trends. Int J Health Geogr 8, 71 .

23. Gosselin NH, Brunet RC, Carrier G et al. (2006) Reconstruction of methylmercury intakes in indigenous populations from biomarker data. J Expo Sci Environ Epidemiol 16, 19-29.

24. Dórea JG (2009) Fish: biomarkers: blood or hair? Public Health Nutr 12, 2536-2537. 
25. Oliveira RC, Dórea JG, Bernardi JVE et al. (2010) Fish consumption by traditional subsistence villagers of the Rio Madeira (Amazon): impact on hair-mercury. Ann Hum Biol 37, 629-642.

26. Barbosa AC, Boischio AA, East GA et al. (1995) Mercury contamination in the Brazilian Amazon. Environmental and occupational aspects. Water Air Soil Poll 80, 109-121.

27. Dórea JG, Barbosa AC, Ferrari I et al. (2005) Fish consumption (hair mercury) and nutritional status of Amazonian Amer-Indian children. Am J Hum Biol 17, 507-514.

28. Marques RC, Dórea JG, Bernardi JV et al. (2008) Maternal fish consumption in the nutrition transition of the Amazon Basin: growth of exclusively breastfed infants during the first 5 years. Ann Hum Biol 35, 363-377.

29. Fearnside PM (2005) Brazil's Samuel Dam: lessons for hydroelectric development policy and the environment in Amazonia. Environ Manage 35, 1-19.

30. Marques RC, Dórea JG, Bastos WR et al. (2007) Maternal mercury exposure and neuro-motor development in breastfed infants from Porto Velho (Amazon), Brazil. Int J Hyg Env Health 210, 51-60.

31. World Health Organization (2007) WHO Anthro for Personal Computers, Version 2. Software for Assessing Growth and Development of the World's Children. Geneva: WHO; available at http://www.who.int/childgrowth/software/en/

32. Gesell A (2003) A criança de 0 a 5 anos, 6th ed., pp. 20-300. São Paulo: Martins Fontes.

33. Gesell A \& Amatruda CS (2000) Psicologia do desenvolvimento-do lactente a criança pequena, bases neuropsicológicas e comportamentais, 1st ed., pp. 30-106. São Paulo: Atheneu.

34. Tang D, Li TY, Liu JJ et al. (2008) Effects of prenatal exposure to coal-burning pollutants on children's development in China. Environ Health Perspect 116, 674-679.

35. Fonseca MF, Dórea JG, Bastos WR et al. (2008) Poor psychometric scores of children living in isolated riverine and agrarian communities and fish-methylmercury exposure. Neurotoxicology 29, 1008-1015.

36. Roos N, Wahab MA, Chamnan C et al. (2007) The role of fish in food-based strategies to combat vitamin A and mineral deficiencies in developing countries. J Nutr $\mathbf{1 3 7}$ 1106-1109.

37. Benefice E, Monrroy SJ \& Rodriguez RW (2008) A nutritional dilemma: fish consumption, mercury exposure and growth of children in Amazonian Bolivia. Int J Environ Health Res 18, 415-427.
38. Barbieri FL, Cournil A \& Gardon J (2009) Mercury exposure in a high fish eating Bolivian Amazonian population with intense small-scale gold-mining activities. Int J Environ Health Res 19, 267-277.

39. Muniz PT, Castro TG, Araújo TS et al. (2007) Child health and nutrition in the Western Brazilian Amazon: populationbased surveys in two counties in Acre state. Cad Saude Publica 23, 1283-1293.

40. Pinheiro MC, Crespo-López ME, Vieira JL et al. (2007) Mercury pollution and childhood in Amazon riverside villages. Environ Int 33, 56-61.

41. Boischio AA \& Barbosa A (1993) Exposure to organic mercury in riparian populations on the Upper Madeira river, Rondonia, Brazil, 1991: preliminary results. Cad Saude Publica 9, 155-160.

42. Passos CJ \& Mergler D (2008) Human mercury exposure and adverse health effects in the Amazon: a review. Cad Saude Publica 24, Suppl. 4, s503-s520.

43. Chevrier C, Sullivan K, White RF et al. (2009) Qualitative assessment of visuospatial errors in mercury-exposed Amazonian children. Neurotoxicology 30, 37-46.

44. Dórea JG (2009) Comparing fish-mercury exposed Amazonian children: should not we consider thimerosalpreserved vaccines? Neurotoxicology 30, 485-486.

45. Marques RC, Dórea JG, Bernardi JV et al. (2009) Prenatal and postnatal mercury exposure, breastfeeding and neurodevelopment during the first 5 years. Cogn Behav Neurol 22, 134-141.

46. Kramer MS, Aboud F, Mironova E et al. (2008) Breastfeeding and child cognitive development: new evidence from a large randomized trial. Arch Gen Psychiatry 65, 578-584.

47. Oken E (2010) Fish intake and mercury levels: only part of the picture. J Pediatr 157, 10-12.

48. Belfort MB, Rifas-Shiman SL, Rich-Edwards JW et al. (2008) Infant growth and child cognition at 3 years of age. Pediatrics 122, e689-e695.

49. Grandjean P \& Landrigan PJ (2006) Developmental neurotoxicity of industrial chemicals. Lancet 368, 2167-2178.

50. Paine PA, Dórea JG, Pasquali L et al. (1992) Growth and cognition in Brazilian school children. Int J Behav Dev 15, 169-183.

51. Cheung Y \& Ashorn P (2009) Continuation of linear growth failure and its association with cognitive ability are not dependent on initial length-for-age: a longitudinal study from 6 months to 11 years of age. Acta Paediatr (Epublication ahead of print version). 